\title{
Incidence of Tomato spotted wilt virus (Bunyaviridae) and Tobacco Thrips in Virginia-Type Peanuts in North Carolina
}

\author{
L. E. Garcia, Former Graduate Student, and R. L. Brandenburg, Extension Entomologist, Department of Ento- \\ mology, North Carolina State University, Raleigh 27695; and J. E. Bailey, Extension Plant Pathologist, North \\ Carolina State University, Raleigh 27695
}

\begin{abstract}
Garcia, L. E., Brandenburg, R. L., and Bailey, J. E. 2000. Incidence of Tomato spotted wilt virus (Bunyaviridae) and tobacco thrips in Virginia-type peanuts in North Carolina. Plant Dis. 84:459464.

Virginia-type peanut (Arachis hypogaea) cultivars were monitored for incidence of Tomato spotted wilt virus (TSWV) and abundance of Frankliniella fusca, the tobacco thrips, in North Carolina during 1995 and 1996. A preliminary evaluation of 225 peanut genotypes for TSWVresistant or -tolerant genotypes was conducted in 1995. The incidence of TSWV in cultivar NC9 was twice that of cultivar NC-V11. In 1996, field trials designed to evaluate TSWV susceptibility were conducted with three widely grown commercial peanut cultivars in North Carolina. They were NC-9, NC-V11, and NC-12C, a newly released cultivar. A randomized complete block design was utilized at three locations. Disease incidence was evaluated weekly from 2 weeks postplanting until 2 weeks prior to harvest. Mechanical inoculation of the three cultivars resulted in no difference in relative leaf virus titer as determined from optical density readings following DAS-ELISA for 4 successive weeks beginning at 13 days postinoculation. NC-9 ranked highest in incidence of disease (7\%), followed by NC-12C (6\%) and NC-V11 (5\%). Thrips counts were greatest on NC-V11, followed by NC-9 and NC-12C. Disease incidence overall was $5.96 \%$, but ranged from 3.08 to $11.15 \%$ among the three sites. Yield was affected by the temporal occurrence of symptoms beginning at the fifth week postplanting. Greatest yield losses occurred in those plants with the earliest visible foliar symptoms.
\end{abstract}

Additional keywords: disease management, peanut virus disease

Tomato spotted wilt virus (TSWV) causes significant disease of many food and ornamental crops, with over 600 recognized host species (15). Some control of the disease was achieved in the 1940s and 1950s through control of the thrips vector in Europe (20). Subsequent spread of TSWV has been attributed to spread of western flower thrips, Frankliniella occidentalis. In the United States, TSWV first appeared in ornamental crops on the West Coast. The virus affected peanuts in Texas in 1974 and caused yield losses by the mid1980s (25). Yield reductions were observed in Georgia by 1993 (11). TSWV was first recognized in North Carolina peanuts in 1990, and by 1995 it was reported throughout the peanut producing area of the state. However, there have been no appreciable yield reductions attributable to TSWV in North Carolina.

TSWV is capable of replication within thrips (30) and is vectored in a persistent fashion $(21,22)$ by thrips species. Thrips

Corresponding author: L. E. Garcia

E-mail: 1loyd.garcia@ncmail.net

Accepted for publication 27 December 1999.

Publication no. D-2000--0216-01R

(C) 2000 The American Phytopathological Society acquire the virus as first instar larvae (17) and are then capable of transmitting the disease after a latent period of 3 to 7 days (20). It was initially thought that only adults were able to transmit the virus; however, it has been shown that TSWV can be transmitted by second instar $F$. occidentalis larvae and adults (32). Adult thrips are capable of vectoring the virus in as little as 5 min (21), making control of spread of TSWV with insecticides difficult. TSWV is not transmitted transovarially (31) and is not seed-borne. Mound (18) lists seven confirmed vector species: $F$. fusca, $F$. intonsa, $F$. occidentalis, $F$. schultzei, Thrips palmi, T. setosus, and T. tabaci. Three of these species, F. occidentalis, F. fusca, and T. tabaci, are found in association with agroecosystems in North Carolina (13). Of this group, F. occidentalis and T. tabaci occur only occasionally in North Carolina peanuts (1).

Disease management based on thrips control in peanut is difficult. When insecticides are utilized, TSWV incidence has not been reduced (28). However, cultural techniques, such as cultivar selection, field selection, plant spacing, and planting date, have been successful in limiting TSWV epidemics (5). Experiments conducted in Texas (2) and Georgia $(11,12)$ have documented up to a twofold difference among peanut cultivars in the incidence of TSWV due to cultivar selection. Transgenic technology may also become a useful tool in the future (29); however, identification and utilization of peanut cultivars that are either resistant or tolerant to TSWV, in combination with cultural techniques such as field selection and planting date, has offered short-term protection in Georgia (4).

Prior to 1996, no large-scale field evaluations had been conducted to identify TSWV-susceptible and -resistant cultivars among North Carolina grown peanut cultivars. The three selected cultivars evaluated in this test were chosen because preliminary reports indicated the possibility of a twofold difference in symptom expression between NC-9 and NC-V11, and because of seed availability and their wide usage in North Carolina. This experiment was conducted to determine TSWV resistance or tolerance among these Virginia-type peanut cultivars grown under field conditions in North Carolina.

\section{MATERIALS AND METHODS}

1995 experimental field design. Initial evaluations of TSWV incidence in Virginia-type peanut cultivars were made at two locations in 1995 in North Carolina. One was in Bertie County, at the Peanut Belt Research Station, Lewiston, where thrips feeding damage and TSWV incidence in peanut cultivars NC-9 and NCV11 were assessed. Each plot consisted of two rows $27 \mathrm{~m}$ long (240 plants per row). Because of field constraints, plots of NC-9 and NC-V11 were replicated three and four times, respectively. Both cultivars were located within a 2.4-ha planting of several different peanut cultivars.

The second location was an on-farm test of 225 peanut genotypes in Gates County that was established to evaluate Sclerotinia minor resistance. This test was randomly arranged in plots of 14 plants each, with four replications per genotype. Based on a visual rating of TSWV symptoms in the $S$. minor test site conducted on 24 July 1995, peanut genotypes were observed that exhibited a wide range of TSWV symptom expression. This range in symptom expression provided a first opportunity to assess TSWV susceptibility among peanut breeding lines in North Carolina. Six genotypes representing a range of visual symptoms were selected for assay by double antibody sandwich enzyme-linked immunosorbent assay (DAS-ELISA) to de- 
termine TSWV incidence in October. All plants in each of the six genotypes were assayed.

Bertie County field evaluation. The presence of thrips feeding damage on 50 randomly selected unopened leaflets per plot was determined. Damage was evaluated on three occasions: 22, 38, and 43 days postplanting. TSWV incidence was recorded as the number of plants per plot with visual TSWV symptoms, which included combinations of leaflet bronzing, petiole twisting, concentric ring spotting, and plant stunting or wilting. No laboratory analysis was conducted to confirm presence of TSWV antigens. Plots were evalu- ated twice: 91 and 113 days postplanting.

Gates County field evaluation. Two newly opened leaflets and two root samples were taken from all surviving plants in each plot of six selected genotypes in October 1995. The leaflet and root samples from each plant were pooled separately and assayed by DAS-ELISA using a kit obtained from Agdia Inc. (Elkhart, IN). Each pooled sample was tested in three microtiter plate wells. Healthy controls, positive TSWV controls, and grinding buffer blanks were included on each plate. Plates were read at an optical density of $405 \mathrm{~nm}$ (Molecular Devices, Vmax Kinetic Microplate Reader, Sunnyvale, CA). A well was
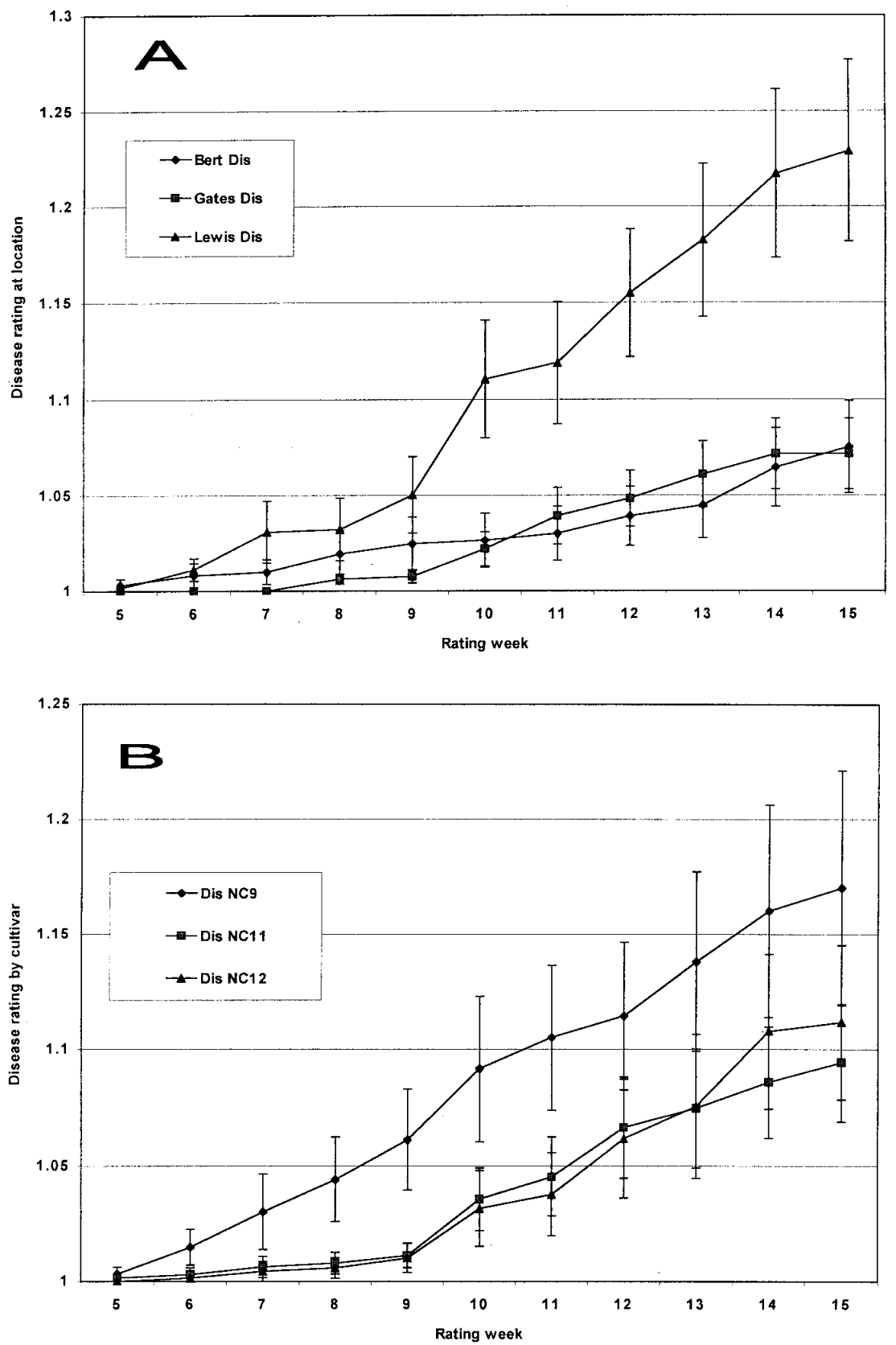

Fig. 1. Mean Tomato spotted wilt virus (TSWV) disease rating at week 5 postplanting (A) by location and (B) by cultivar. Gates location was planted 2 weeks later than Bertie and Lewiston locations, so week 5 at Bertie and Lewiston corresponds to 13 June and at Gates corresponds to 27 June. classified as positive if its optical density value was greater than the plate's healthy control value plus three standard deviations.

1996 experimental field design. Three Virginia-type peanut cultivars were selected for field evaluation in 1996 based on the previous season's results. Cultivars were selected that represented a range of TSWV susceptibility. NC-9 was considered susceptible, and NC-V11 and NC-12C were considered moderately resistant. NC9 and NC-V11 are among the top five cultivars with the highest production acreage in North Carolina. NC-12C is a newly released cultivar that has grown in popularity. Peanuts were planted in a randomized block design at three locations in the production area of northeastern North Carolina. Each treatment was a portion of a larger peanut field and consisted of a site 45 by $19.8 \mathrm{~m}$. At each location, there were 12 plots, or four replications per cultivar. Replicated plots were assigned randomly and consisted of six rows, each $7.2 \mathrm{~m}$ in length. The middle two rows of the plots were evaluated for TSWV incidence, thrips populations, and per plant yield. Plants within the middle two rows were thinned to a $0.25-\mathrm{m}$ spacing in an attempt to increase disease incidence $(3,16)$. There was a maximum of 56 plants per replicated plot. All plots were separated by two rows, or $1.8 \mathrm{~m}$, of Tamrun 88 , a cultivar highly susceptible to TSWV (2).

Two study sites were located in Bertie County, the Griffin Farm (Bertie) and the Peanut Belt Research Station (Lewiston). The third treatment location was in Gates County, at the Griffin Farm. The soil type at Bertie is Norfolk sandy loam, at Lewiston is Goldsboro sandy loam, and at Gates is Craven-Shabuta. Production practices were followed according to NC Cooperative Extension Service recommendations (26), except that no insecticides were used. Fungicides and herbicides were used as part of a typical pest management program.

Seeds were sown with a conventional six-row planter on 9 May 1996 at the Bertie and Lewiston sites. Rain delayed planting at the Gates site until 23 May. Therefore, all collections at Gates were conducted 2 weeks later than those at Bertie and Lewiston. For purposes of data analysis, however, sampling dates were calculated as time from planting.

Disease rating. The middle two rows of each plot were rated for visual symptoms of TSWV disease every week from 2 weeks postplanting until 2 weeks prior to harvest, a total of 15 weeks. Plants were considered symptomatic if one or more leaves displayed TSWV's characteristic concentric rings. Ratings were as follows: $1=$ no symptoms; $2=1$ to $33 \%$ of the leaves with symptoms; $3=34$ to $66 \%$ of the leaves with symptoms; $4=67$ to $100 \%$ of the leaves with symptoms; and $5=$ plant death. Two leaflets from each symptomatic 
plant were analyzed by DAS-ELISA using kits from Agdia. Plants were considered positive if they had both visual foliar symptoms and a positive DAS-ELISA absorbance value that was three times the standard deviation of the optical density reading of five control wells plus the mean of five control wells. Positive plants were flagged in the field.

Thrips collection. Beginning at 14 days postplanting, samples were collected to monitor thrips populations. Twenty individual unopened quadrifoliate leaf samples were collected from the middle two rows of each plot at each sampling period. Samples were collected every 7 days for 13 weeks. Plot samples were collected and stored in $20-\mathrm{ml}$ scintillation vials partially filled with $70 \%$ ethanol. Samples were examined under a dissecting microscope, and the number of tobacco thrips adults, larvae, or other thrips species was recorded.

Yield determination. Plants were harvested individually on 2 and 3 October at Bertie and Lewiston, respectively, and on 18 October at Gates. Plants were bundled by treatment and plot and stored until the pods were dry, then removed by hand and placed in a paper bag for an additional drying period of 2 weeks. Total pod weight and pod count per plant were recorded.

Mechanical inoculation. Twelve plants from each of the three cultivars were mechanically inoculated on 17 June 1996 with TSWV. Each peanut seed was sown in sterile soil in a $10-\mathrm{cm}$ plastic pot. The isolate of TSWV used was obtained from peanut plants grown in North Carolina and maintained by J. Moyer, Department of Plant Pathology, NCSU. All leaflets of the youngest fully expanded leaf were inoculated at 14-days postplanting, when the plants had two or three leaves. The TSWV isolate was maintained in Emilia sonchifolia, flora's paintbrush, and mechanically transferred to Nicotiana benthamiana seedlings, where it was allowed to increase for 1 week prior to peanut inoculation. Inoculation was conducted with triturated extract from infected leaves ground in buffer (0.01 M Tris, 0.01 $\mathrm{M} \mathrm{Na} \mathrm{SO}_{3}$, and $0.1 \%$ Cysteine $\mathrm{HCl}, \mathrm{pH} 7.8$ ) at $1: 5$ (wt/vol). Beginning 13 days postinoculation, two leaflets from the youngest fully expanded tetrifoliate leaf were removed from each plant weekly for 4 weeks. Virus titer in the leaflets was determined by DAS-ELISA. Each leaflet was ground in a 1:10 ratio of plant to extraction buffer and transferred to three wells on a microtiter plate. The optical density (OD) was read 1 hour after addition of substrate buffer. A sample was considered positive if its value was greater than three times the standard deviation of the OD value of five predesignated healthy control wells plus the mean of five healthy control wells on the same microtiter plate.

Data analysis. Weekly disease ratings and thrips counts from all three locations were analyzed by analysis of variance (SAS Institute, Cary, NC), treating cultivars and locations as fixed effects. The protected LSD procedure was used to compare means for locations and means for cultivars averaged over locations. Similar analysis was carried out on log transformed larval and adult counts for each week.

\section{RESULTS}

1995 Bertie County. Any plant that exhibited typical thrips feeding damage, including misshapen leaves and/or stippled leaves, was considered to be a damaged plant. Thrips damage, although not significant, was greater in NC-V11 than in NC-9. At 22 days postplanting, $12 \%$ of NC-9 plants and $16 \%$ of NC-V11 plants exhibited feeding damage. At 38 days postplanting $37 \%$ of the NC-9 plants and $55 \%$ of the NC-V11 plants were damaged. At 43 days postplanting, feeding damage was $36 \%$ of the NC- 9 and $51 \%$ of the NC-V11.

The number of plants expressing TSWV symptoms was higher in NC-9 than in NCV11. NC-9 had an average symptom level of $8.67 \%$ at 91 days postplanting and $3.33 \%$ at 113 days postplanting. NC-V11 symptom level was $2.25 \%$ at 91 days postplanting and $1.5 \%$ at 113 days postplanting. The growth of healthy foliage concealing symptomatic vegetation and a premature drop of the symptomatic foliage contributed to an apparent decrease in infection levels from 91 to 113 days postplanting.

1995 Gates County. Incidence of TSWV was greater in NC-9 than in NCV11. Of 42 NC-9 plants sampled, $47.6 \%$ tested positive for TSWV; 20 root and three leaflet samples were positive. Of 41 NC-V11 plants sampled, $23.8 \%$ were positive, nine root samples and three leaflet samples. A plant was considered positive if either root or foliage tested positive. In the remaining four genotypes, the incidence of TSWV was $23 \%$ in NC-7/NC-9, $17.5 \%$ in NC-V11/NCAc18016, 55.5\% in NC-V11/

Table 2. Peanut pod weight and pod count per plant, and average weight per pod, at three locations in northeastern North Carolina and on three Virginia-type peanut cultivars

\begin{tabular}{lccc}
\hline & Avg. g/plant $\mathbf{~}^{\mathbf{y}}$ & Pod count/plant $^{\mathbf{y}}$ & Avg. g/pod $\mathbf{p o}^{\mathbf{y}}$ \\
\hline Location & & & \\
Bertie & $117.85 \mathrm{a}^{\mathrm{z}}$ & $56.59 \mathrm{a}$ & $2.04 \mathrm{a}$ \\
Gates & $70.97 \mathrm{c}$ & $41.64 \mathrm{~b}$ & $1.70 \mathrm{~b}$ \\
Lewiston & $85.24 \mathrm{~b}$ & $45.24 \mathrm{~b}$ & $1.80 \mathrm{~b}$ \\
Cultivar & & & \\
NC-9 & $86.26 \mathrm{~b}$ & $45.42 \mathrm{~b}$ & $1.81 \mathrm{~b}$ \\
NC-V11 & $90.97 \mathrm{ab}$ & $50.93 \mathrm{a}$ & $1.73 \mathrm{c}$ \\
NC-12C & $96.83 \mathrm{a}$ & $47.12 \mathrm{~b}$ & $1.99 \mathrm{a}$ \\
\hline
\end{tabular}

y Number of replicate plots per mean was 12 .

${ }^{\mathrm{z}}$ Means with same letter not significantly different at $5 \%$ (LSD procedure).

Table 1. Average per plant pod yield of three Virginia-type peanut cultivars in three locations in northeastern North Carolina, 1996

\begin{tabular}{|c|c|c|c|c|c|c|c|c|c|}
\hline \multirow[b]{3}{*}{ Location } & \multirow[b]{3}{*}{ Cultivar } & \multicolumn{6}{|c|}{ Sample period $^{\mathrm{w}}$} & \multirow{2}{*}{\multicolumn{2}{|c|}{$\begin{array}{c}\text { Asymptomatic plants } \\
\text { at harvest }\end{array}$}} \\
\hline & & \multicolumn{2}{|c|}{ Weeks 7-10 } & \multicolumn{2}{|c|}{ Weeks 11-13 } & \multicolumn{2}{|c|}{ Weeks 15-17 } & & \\
\hline & & $\mathrm{g}^{\mathrm{x}}$ & Plants $^{\mathrm{y}}$ & g & Plants & g & Plants & g & Plants $^{\mathrm{Z}}$ \\
\hline \multirow[t]{3}{*}{ Bertie } & NC-9 & 0 & 3 & 0 & 0 & 0 & 0 & 116.4 & 193/196 \\
\hline & NC-V11 & 9.4 & 1 & 74.9 & 3 & 61.3 & 4 & 115.3 & $178 / 186$ \\
\hline & $\mathrm{NC}-12 \mathrm{C}$ & 0 & 0 & 0 & 0 & 86.9 & 9 & 126.7 & $177 / 186$ \\
\hline \multirow[t]{3}{*}{ Gates } & NC-9 & 8.5 & 2 & 18.5 & 6 & 0 & 0 & 70.0 & $208 / 216$ \\
\hline & NC-V11 & 0 & 1 & 20.9 & 4 & 72.0 & 3 & 73.7 & 206214 \\
\hline & $\mathrm{NC}-12 \mathrm{C}$ & 0 & 1 & 52.7 & 1 & 29.0 & 2 & 73.8 & $215 / 219$ \\
\hline \multirow[t]{3}{*}{ Lewiston } & NC-9 & 0.7 & 5 & 16.1 & 12 & 43.7 & 8 & 86.2 & $159 / 184$ \\
\hline & NC-V11 & 7.00 & 1 & 23.8 & 10 & 41.2 & 4 & 91.6 & $194 / 209$ \\
\hline & $\mathrm{NC}-12 \mathrm{C}$ & 7.9 & 1 & 31.0 & 17 & 82.6 & 8 & 97.8 & $205 / 231$ \\
\hline
\end{tabular}

\footnotetext{
${ }^{\mathrm{w}}$ Number of weeks postplanting.

x Per plant averages were based on the time from planting when Tomato spotted wilt virus (TSWV) symptoms were first observed.

y Total number of plants with symptoms.

${ }^{\mathrm{z}}$ Total number of asymptomatic plants at the end of the test over total number of plants observed.
} 
$\mathrm{NC}-10 \mathrm{C}$, and $32 \%$ in $\mathrm{NC}-\mathrm{V} 11 / \mathrm{NCAc}$ 18229.

1996 disease incidence. Overall, incidence of disease was $5.99 \%$ of all plants across cultivars and locations. It was greatest at Lewiston at $11.06 \%$, followed by the Bertie location with a $3.63 \%$ infection level and the Gates location with an infec- tion level of $3.08 \%$. Disease symptoms began to appear in week 5, 50 days after planting (Fig. 1A). Total mean disease rating per plant was significantly higher at Lewiston than at Bertie or Gates locations, which began on week 9 and continued throughout the season. Disease ratings at Bertie and Gates sites were not signifi-

Table 3. Average seasonal counts of adult and larval Frankliniella fusca in 1996 at three locations in northeastern North Carolina and on three Virginia-type peanut cultivars

\begin{tabular}{lccc}
\hline & No..$^{y}$ of plots & Adult mean counts & Larvae mean counts \\
\hline Location & & & \\
Bertie & 156 & $3.5 \mathrm{~b}^{\mathrm{z}}$ & $8.6 \mathrm{~b}$ \\
Gates & 144 & $2.5 \mathrm{c}$ & $4.4 \mathrm{c}$ \\
Lewiston & 147 & $4.6 \mathrm{a}$ & $15.4 \mathrm{a}$ \\
Cultivar & & & \\
NC-9 & 149 & $3.6 \mathrm{ab}$ & $8.6 \mathrm{ab}$ \\
NC-V11 & 149 & $3.7 \mathrm{a}$ & $10.1 \mathrm{a}$ \\
NC-12C & 149 & $3.1 \mathrm{~b}$ & $7.6 \mathrm{~b}$ \\
\hline
\end{tabular}

${ }^{y}$ Number of replicated plots sampled 13 times during the season. Each plot sample consisted of 20 unopened tetrafoliate leaves.

${ }^{z}$ Means of thrips counts with same letter do not differ significantly at 5\% (LSD procedure following analysis of $\log$ transformed counts).

cantly different (Fig. 1A). NC-9 consistently had higher disease ratings than NC-V11 and NC-12C. The ratings were significant in weeks $8,9,10$, and 11 (Fig. 1B). Ratings among NC-V11 plants were somewhat higher in weeks 5 through 12 than those of $\mathrm{NC}-12 \mathrm{C}$ plants; however, this condition reversed in weeks 13 through 15 (Fig. 1B).

Disease symptoms from weeks 5 through 8 tended to occur first in NC-9. As the season progressed, from week 9 through week 12, the incidence of TSWV symptomatic plants increased among all cultivars. Overall, more plants became infected during weeks 9 through 12, and the number of additional symptomatic plants decreased after week 13 across all cultivars. At Lewiston, the cumulative incidence of peanut plants with TSWV symptoms was higher in NC-9 (25 of 184 plants) than in NC-V11 (15 of 209 plants) (Table 1).

Yield. Number of pods per plant and their mean weights were significantly
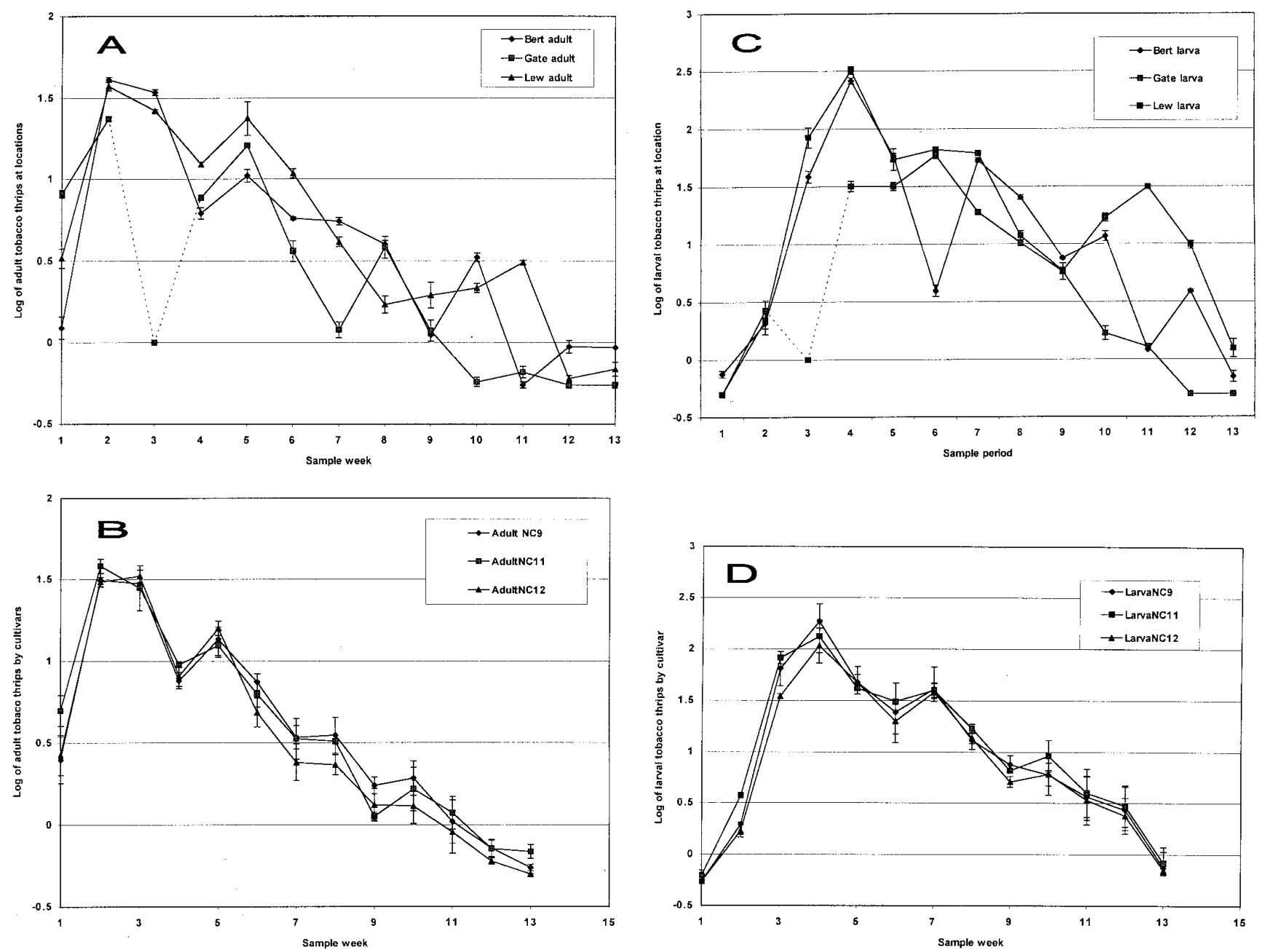

Fig 2. Log of tobacco thrips counts taken from 20 unopened quadrifoliate leaves per plot: (A) adults on all varieties by location, (B) adults at all three locations by variety, (C) larvae on all varieties by location, and (D) larvae at all locations by variety. Count data from Gates location for week 3 is missing. It was planted 2 weeks later than Bertie and Lewiston locations, so week 1 at the latter sites corresponds to 16 May and at Gates site corresponds to 30 May. 
greater at the Bertie location, followed by the Lewiston and Gates sites (Table 2). Among the cultivars and across locations, $\mathrm{NC}-12 \mathrm{C}$ had significantly greater yield per plant than NC-9, but not significantly greater than NC-V11. Mean weight per pod was highest with NC-12C. NC-V11 had significantly greater mean pod count per plant (Table 2). Plants that became symptomatic early in the season had lower yields than plants that became symptomatic later in the season and those that remained asymptomatic (Table 1).

Thrips counts. Season-long counts of adult and larval $F$. fusca were significantly higher at Lewiston than at the Gates or Bertie locations (Table 3); however, weekly counts of adults and larvae fluctuated (Fig. 2A and C). Overall, counts of adult and larval tobacco thrips were higher in NC-V11 than in the other two cultivars, but only significantly greater than NC-12C (Table 3). Adult $F$. fusca counts peaked in weeks 2 and 3 , or 14 and 21 days postplanting, at all locations and across all cultivars (Fig. 2A and B). Larval $F$. fusca counts for Lewiston and Bertie peaked in week 4 , or 28 days postplanting, and at week 6, 42 days postplanting, for Gates (Fig. 2C). Larval counts by cultivar peaked consistently at week 4 (Fig. 2D). Data from Gates for week 3 and from all but one set of replicates at Lewiston in week 5 were misplaced and are not represented in the data for those periods.

Mechanical inoculations. Inoculated peanut plants all had consistently high DAS-ELISA absorbance values (Fig. 3), with no differences among the three cultivars. All three cultivars reached their highest virus titer on either the first (NC-9 and $\mathrm{NC}-12 \mathrm{C}$ ) or the second sampling date (NC-V11), with decreasing absorbance values thereafter.

\section{DISCUSSION}

Field evaluations were more useful in this study than mechanical inoculations of peanut cultivars in evaluating TSWV resistance. The potential for multiple introductions of a virus across an entire leaf surface during mechanical inoculation may present a higher level of disease pressure than individual thrips inoculation. As a result, mechanical inoculations probably overwhelm subtle variations in disease tolerance or resistance mechanisms, which may be more apparent under field conditions.

A general correlation in 1996 occurred between thrips populations and incidence of disease at Lewiston, but was not present among peanut cultivars, nor across locations. The lack of a relationship between high thrips populations and high incidence of TSWV was corroborated by preliminary observations in North Carolina of thrips damage and disease occurrence with NC-9 and NC-V11 in 1995. Lower thrips populations, as at the Gates location, often re- sulted when peanuts were planted late (24). Variation among symptomatic cultivars may also be related to differences in thrips survival rates on TSWV-infected peanuts of different cultivars. The variation in disease symptoms among cultivars, especially evident between NC-9 and NC-V11 at Lewiston, suggests the presence among Virginia-type peanuts of a range of TSWVresistant or -tolerant cultivars that can be selected and utilized in peanut production practices for North Carolina. However, interpretation of the results was difficult due to the relatively low incidence of symptomatic plants across cultivars in 1996 and the lack of a TSWV susceptible cultivar to use as a known reference. Until either disease pressure increases in North Carolina or currently grown peanut cultivars exhibit more susceptibility to TSWV, the selection of resistant cultivars will remain difficult.

Effect of location was a significant factor in disease incidence in 1996, and it is important to consider the implications of the comparatively high incidence of TSWV at Lewiston (11\%) compared with the more moderate disease incidence at the Bertie (3.52\%) and Gates (3.08\%) locations as this disease becomes more abundant in peanut producing areas of the state. Lewiston is the site of the Peanut Belt Research Station and is subject to production of peanuts in closely arrayed fields. At the other two sites, peanuts or other TSWV hosts are not produced in adjacent fields year after year. If thrips populations and virus levels are not static across peanut production areas, it is plausible that virus inoculum is increasing, or decreasing, at different rates at different locations due to variations in the densities of viral plant hosts and thrips populations. Alternatively, viruliferous thrips may migrate preferentially at different locations based on plant host attractiveness or on localized environmental factors that affect the number of thrips vectors migrating into production fields.

Viruliferous thrips and infected plant hosts are sources of TSWV in the spring. The importance of weeds as alternate hosts has long been recognized in the epidemiology of TSWV $(9,23)$. Tobacco thrips have been shown to overwinter in Florida (27), Georgia $(6,7,8)$, Louisiana (19), North Carolina (1,10; L. E. Garcia, R. L. Brandenburg, and G. G. Kennedy, unpublished), and South Carolina (14). It is possible the virus overwinters in thrips and that these thrips are the source of primary infection of peanuts. However, overwintering thrips are probably more important as a shortterm bridge between alternate weed hosts and subsequent virus spread to offspring during the spring than they are as a primary source of infection in spring planted peanuts.

From a management perspective, the selection of peanut cultivars with low incidence of disease is obviously preferred because it requires no additional inputs of capital, little or no educational programming to implement, and it offers environmental protection. This study has shown that there are differences in the level of

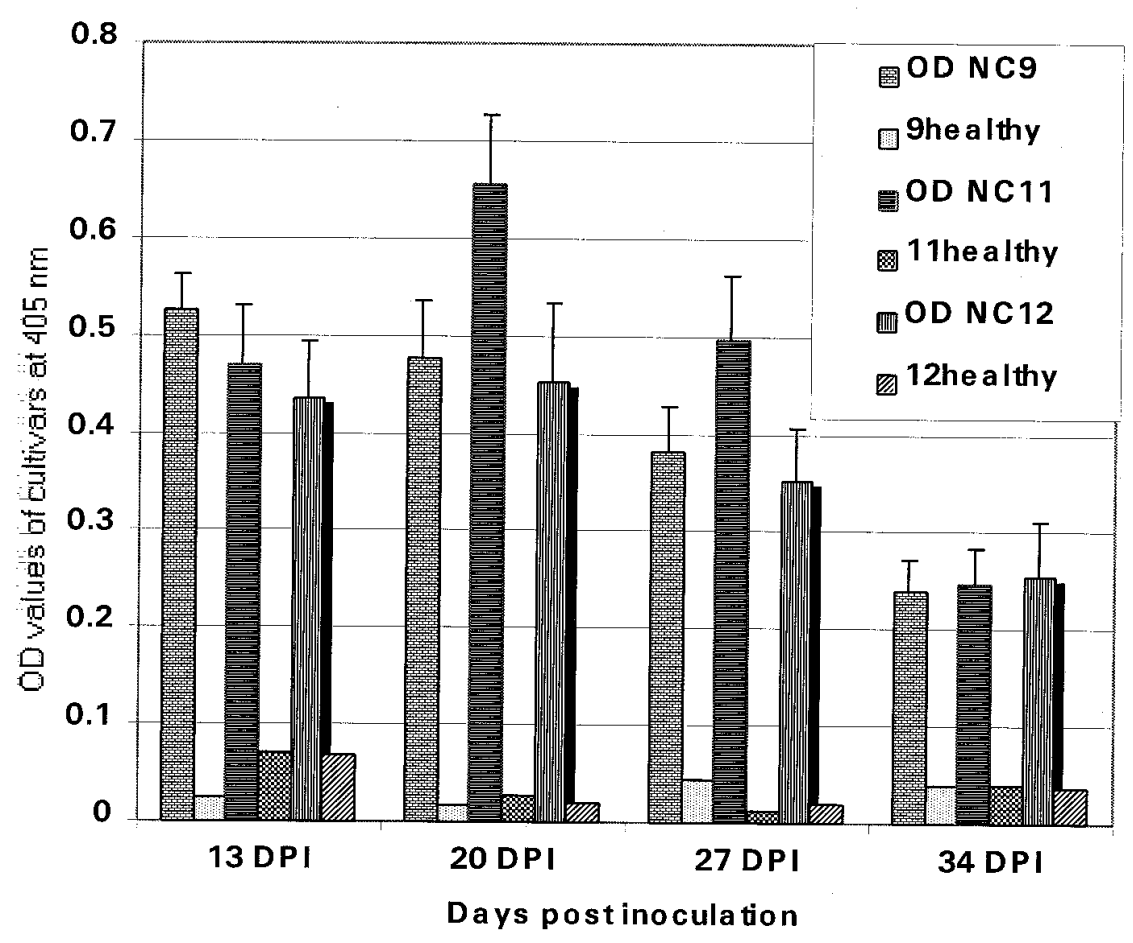

Fig 3. Mean double antibody sandwich enzyme-linked immunosorbent assay (DAS-ELISA) absorbance of leaf samples taken from three peanut cultivars beginning 13 days postmechanical inoculation and continuing for 4 weeks at 7-day intervals in 1996. 
TSWV infection among the peanut cultivars grown in North Carolina. The differences between infection levels of NC-9 compared with $\mathrm{NC}-\mathrm{V} 11$ and $\mathrm{NC}-12 \mathrm{C}$ may warrant a shift in production away from more susceptible peanut cultivars. Additional cultivars need to be evaluated under greater disease incidence to find a cultivar with significant TSWV tolerance or resistance and with acceptable agronomic characteristics. Although not always practical, the careful selection of production fields for those with low levels of disease incidence or inoculum, as recommended in Georgia's TSWV Risk Assessment Index (5), together with the destruction of known TSWV weed hosts may also reduce the buildup of inoculum in the environment and the overall disease incidence.

\section{ACKNOWLEDGMENTS}

We thank Scott Kennedy, Brian Royals, Brenda Watson, and Ian Winborne for technical assistance. Steve Barnes coordinated the field selection and preparation at Lewiston Peanut Belt Research Station. Tom Isleib's assistance was instrumental in the selection of the peanut cultivars used in this study. Cavell Browning provided advice with statistical analysis. Katrin Hoffmann provided generous support in the field and lab as well as advice with ELISA procedures. The North Carolina Department of Agriculture and Consumer Services created the opportunity and lent valuable resources to this work. Partial funding for this project was provided by the North Carolina Peanut Grower's Association, Inc., and USAID Peanut CRSP (Grant DPN-4048-G-00-0041-00).

\section{LITERATURE CITED}

1. Barbour, J. D., and Brandenburg, R. L. 1994. Vernal infusion of thrips into North Carolina peanut fields. J. Econ. Entomol. 87:446-451.

2. Black, M. C., and Smith, D. H. 1987. Spotted wilt and rust reactions in south Texas among selected peanut genotypes. Proc. Am. Peanut Res. Educ. Soc. 19:31.

3. Black, M. C., Tewolde, H., Fernandez, C. J., and Schubert, A. M. 1994. Effect of seeding rate, irrigation, and cultivar on spotted wilt, rust, and southern blight diseases of peanut. (Abstr.) Proc. Am. Peanut Res. Educ. Soc. 26:50.

4. Brown, S. L., Todd, J. W., and Culbreath, A. K. 1996. Effect of selected cultural practices on incidence of tomato spotted wilt virus and populations of thrips vectors in peanuts. Acta Hortic. 431:491-498.

5. Brown, S. L., Todd, J. W., Culbreath, A. K.,
Baldwin, J., and Beasley, J. 1999. Tomato spotted wilt of peanut: Identifying and avoiding high-risk situations. Univ. Ga.Coop. Ext. Bull. 1165.

6. Buntin, G. D., and Beshear, R. J. 1995. Seasonal abundance of thrips (Thysanoptera) on winter small grains in Georgia. Environ. Entomol. 24:1216-1223.

7. Chamberlin, J. R., Culbreath, A. K., Todd, J. W., and Demski, J. W. 1993. Detection of tomato spotted wilt virus in tobacco thrips (Thysanoptera: Thripidae) overwintering in harvested peanut fields. J. Econ. Entomol. 86:40-45.

8. Chamberlin, J. R., Todd, J. W., Beshear, R. J., Culbreath, A. K., and Demski, J. W. 1992. Overwintering hosts and wingform of thrips, Frankliniella spp., in Georgia (Thysanoptera: Thripidae): Implications for management of spotted wilt disease. Environ. Entomol. 21:121-128.

9. Cho, J. J., Mitchell, W. C., Mau, R. F. L., and Sakimura, K. 1987. Epidemiology of tomato spotted wilt virus disease on crisphead lettuce in Hawaii. Plant Dis. 71:505-508.

10. Cho, K., Eckel, C. S., Walgenbach, J. F., and Kennedy, G. C. 1995. Overwintering of thrips (Thysanoptera: Thripidae) in North Carolina. Environ. Entomol. 24:58-67.

11. Culbreath, A. K., Todd, J. W., Branch, W. D., Brown, S. L., Demski, J. W., and Beasley, J. P., Jr. 1994. Effect of new peanut cultivar Georgia Browne on epidemics of spotted wilt. Plant Dis. 78:1185-1189.

12. Culbreath, A. K., Todd, J. W., Demski, J. W., and Chamberlin, J. R. 1992. Disease progress of spotted wilt in peanut cultivars Florunner and Southern Runner. Phytopathology 82:766-771.

13. Eckel, C. S., Cho, K., Walgenbach, J. F., Kennedy, G. G., and Moyer, J. W. 1996. Variation in thrips species composition in field drops and implications for tomato spotted wilt epidemiology in North Carolina. Entomol. Exp. Applic. 78:19-26.

14. Eddy, C. O., and Livingstone, E. M. 1931. Frankliniella fusca Hinds (thrips) on seedling cotton. S.C. Agric. Exp. Stn. Bull. 271.

15. Goldbach, R., and Peters, D. 1994. Possible causes of the emergence of tospovirus diseases. Semin. Virol. 5:113-120.

16. Gorbet, D. W., and Shokes, F. M. 1994. Plant spacing and tomato spotted wilt virus. (Abstr.) Proc. Am. Peanut Res. Educ. Soc. 26:50.

17. Linford, M. B. 1932. Transmission of the pineapple yellow-spot virus by Thrips tabaci. Phytopathology 22:301-324.

18. Mound, L. A. 1996. The Thysanoptera vector species of tospoviruses. Acta Hortic. 431:298309.

19. Newsom, L. D., Roussel, J. S., and Smith, C.
E. 1953. The tobacco thrips, its seasonal history and status as a cotton pest. La. Agric. Exp. Stn. Tech. Bull. 474.

20. Peters, D., Wijkamp, F., van de Wetering, F., and Goldbach, R. 1996. Vector relations in the transmission and epidemiology of tospoviruses. Acta Hortic. 431:29-43.

21. Sakimura, S. 1962. Frankliniella occidentalis (Thysanoptera: Thripidae), a vector of tomato spotted wilt virus, with special reference to the color forms. Ann. Entomol. Soc. Am 55:387-389.

22. Sakimura, S. 1963. Frankliniella fusca, an additional vector for the tomato spotted wilt virus, with notes on Thrips tabaci, another vector. Phytopathology 53:412-415.

23. Samuel, G., Bald, J. G., and Pittman, H. A. 1930. Investigations on spotted wilt of tomatoes. Aust. Counc. Sci. Ind. Res. Bull. 44.

24. Satayavirut, T. 1988. Thrips (Frankliniella fusca Hinds) population, damage, and yield relationship for peanut types and selected peanut cultivars in North Carolina. Ph.D. diss. North Carolina State University, Raleigh.

25. Stewart, J. W., Cole, C., and Lummus, P. 1989. Winter survey of thrips (Thysanoptera: Thripidae) from certain suspected and confirmed hosts of tomato spotted wilt virus in south Texas. J. Entomol. Sci. 24:392-401.

26. Sullivan, G., ed. 1995. Peanuts 1995. N.C. Agric. Ext. Serv. Publ. AG-331.

27. Toapanta, M., Funderburk, J., Webb, S., Chellemi, D., and Tsai, J. 1996. Abundance of Frankliniella spp. (Thysanoptera: Thripidae) on winter and spring host plants. Environ. Entomol. 25:793-800.

28. Todd, J. W., Culbreath, A. K., and Brown, S. L. 1996. Dynamics of vector populations and progress of spotted wilt disease relative to insecticide use in peanuts. Acta Hortic. 431:483-490.

29. Ullman, D. E. 1996. Thrips and tospoviruses: advances and future directions. Acta Hortic. 431: 310-324.

30. Ullman, D. E., German, T. L., Sherwood, J. L., Westcot, D. M., and Cantone, F. A. 1993. Tospovirus replication in insect vector cells: Immunocytochemical evidence that the nonstructural protein encoded by the S RNA of tomato spotted wilt tospovirus is present in thrips vector cells. Phytopathology 83:456463.

31. Wijkamp, I. 1995. Virus-vector relationships in the transmission of tospoviruses. Ph.D diss. Wageningen Agricultural University, Wageningen, Netherlands.

32. Wijkamp, I., and Peters, D. 1993. Determination of the median latent period of two tospoviruses in Frankliniella occidentalis, using a novel leaf disk assay. Phytopathology 83:986991. 